\title{
O tema "Trabalho" em Ciência da Informação: estudo cientométrico
}

\author{
Asa Fujino \\ Doutora; Universidade de São Paulo (USP), São Paulo, SP, Brasil; \\ asa.fujino@gmail.com \\ Adaci A. O. Rosa Silva \\ Doutoranda; Universidade de São Paulo (USP), São Paulo, SP, Brasil; \\ adaci.rs@gmail.com
}

\begin{abstract}
Resumo: Este artigo constitui-se num estudo cientométrico com o objetivo de analisar a produção científica da Ciência da Informação sobre a temática "trabalho" apresentada no ENANCIB de 2007 a 2012 para identificar questões inerentes à realidade sociotécnica que tangencia as discussões sobre a formação e a atuação do profissional da informação. Partiu-se do pressuposto de que compreender o mundo do trabalho a partir dos fatores que reúnem as relações sociais, as técnicas e tecnologias empregadas e as prescrições que orientam suas atividades é essencial para a construção de projetos pedagógicos, considerando novos requisitos de empregabilidade e acesso às oportunidades e qualidade dos postos de trabalho, além das relações com os contextos sociais em que se inserem os mercados de trabalho demandantes. Os resultados evidenciam um aumento na produção sobre o tema, especialmente em 2012, com a inclusão de outros Grupos de Trabalho (GT) na reflexão sobre competências, técnicas, tecnologias e acesso ao emprego, em especial com aspectos de formação e atuação profissional.
\end{abstract}

Palavras-chave: Profissional da informação. Trabalho. Estudo cientométrico. Formação. Atuação.

\section{Introdução}

A Ciência da Informação (CI) como área de estudos interdisciplinar constitui-se, no cenário atual, em forte aliada e orientadora das políticas de ciência e tecnologia no Brasil por contribuir com instrumentos e procedimentos para acompanhar o desenvolvimento científico e avaliar os diferentes aspectos da produção científica de determinada área.

Tal capacidade de reflexão se apoia nos indicadores resultantes de métodos e técnicas informétricas, bibliométricas, econométricas e 
cientométricas (SPINAK, 1998; MACIAS-CHAPULA, 1998) que possibilitam registrar o "estado da arte" das diversas áreas do conhecimento e descrever o processo histórico de desenvolvimento de temas e questões que marcam profundamente a atualidade, principalmente aquelas relacionadas ao papel central da informação e do conhecimento na sociedade contemporânea.

Deste modo, essas questões fornecem subsídios importantes para discussões acadêmico-científicas sobre os impactos econômicos, políticos e sociais decorrentes do intenso processo de globalização e estabelecimento do padrão sociotécnico da produção, comercialização e consumo de bens e serviços, decorrentes da penetrabilidade da tecnologia da informação em todas as esferas da atividade humana (CASTELLS, 2006). Isto é, elas alteram o nível econômico e produtivo, e influenciam a posição do saber nas sociedades, na medida em que o mesmo "saber" também foi profundamente alterado.

Nesse contexto, a informação se torna uma mercadoria extremamente valiosa nos processos decisórios; da mesma forma, o conhecimento deixa de ser um fundamento comum para se associar à eficiência do mundo atual; e a tecnologia configura-se como elemento inerente ao processo de produção, como observado a seguir:

A habilidade ou inabilidade de as sociedades dominarem a tecnologia e, em especial, aquelas que são estrategicamente decisivas em cada período histórico, traça o seu destino, a ponto de podermos dizer que, embora não determine a evolução histórica e a transformação social, a tecnologia (ou a sua falta) incorpora a capacidade de transformação das sociedades, bem como os usos que as sociedades, sempre em um processo conflituoso, decidem dar ao seu potencial tecnológico. (CASTELLS, 2006, p. 44-45).

Assim, a luta pelo conhecimento pode potencializar as disputas, injustiças e exclusão entre as sociedades na medida em que são sofisticados os modos de produzir, armazenar e distribuir informação.

Desde a década de 1990, verifica-se a ampliação de transformações profundas no mundo do trabalho que acarretam na "mundialização" e globalização do capital com o borramento de fronteiras espaciais e culturais. A estrutura social se depara com mudanças bruscas e extensas e com temas como 
cidadania, garantia de emprego e suprimento das necessidades básicas que voltaram, em todo o mundo, a protagonizar as pautas de reivindicações sociais.

Atreladas à questão do trabalho como elemento fundamental para refletir sobre essa disjunção econômica e social, as reivindicações sociais atuais se encaminham para uma dinâmica individualista de sociedade. Com a intensa difusão das tecnologias da informação, ocorre a implementação de novas estratégias e políticas gestoras direcionadas para o trabalho, particularmente no sentido da divisão do trabalho intelectual e da apropriação de seus produtos.

Um dos principais desdobramentos em termos de produção científica que estuda a temática do trabalho é a investigação dos processos que indicam a centralidade ascendente do trabalho em relação direta ao uso da informação, com valor agregado ao processo de tratamento da informação e organização do conhecimento.

Isto porque, na economia da informação, o valor da informação configura-se

[...] como insumo para qualquer atividade, seja ela uma decisão econômica, um processo cultural ou de ensino/aprendizagem, uma pesquisa científica ou tecnológica, está relacionado diretamente ao seu potencial de orientar de forma econômica o dispêndio de energia para a realização desta atividade. (MARCONDES, 2001, p. 61).

Todavia, há necessidade de conhecimento científico sobre outras dimensões do trabalho com a informação potencial, entre elas, os novos requisitos de empregabilidade para acesso às oportunidades de trabalho; a qualidade do posto de trabalho e as relações com os contextos sociais em que se inserem os mercados de trabalho demandantes.

$\mathrm{O}$ fato de o adensamento de profissões associadas à produção, processamento e uso da informação requerer reposicionamento das formas de lidar com o objetivo de melhor compreensão das exigências das vagas de maior prestígio; a remuneração no mercado de trabalho atual para subsidiar a construção de projetos pedagógicos e a consideração das relações entre a formação e o contexto sociocultural, técnico e científico de atuação profissional 
abarcam as possibilidades de inserção profissional no mundo do trabalho em seu sentido mais amplo.

Neste sentido, Fujino (2011) observa que a universidade tem a responsabilidade de investigar fatores e implicações oriundas do contexto dos mercados demandantes, principalmente nas Ciências Sociais Aplicadas, nas quais o exercício profissional pressupõe mobilização de técnicas que lhe são próprias e defende a necessidade de desenvolvimento de métodos pedagógicos inovadores. Com a possibilidade de conciliar a sistematização de experiências no campo aos processos de abstração e reflexão sobre tais práticas é que ocorre a transformação em conhecimentos compartilhados com o grupo, pois são esses os fatores que vão definir os limites da validação da sua formação.

Parte-se, portanto, do pressuposto de que a compreensão do mundo do trabalho dos profissionais da informação, a partir dos fatores que reúnem as relações sociais de trabalho, o ambiente de trabalho, as técnicas e tecnologias empregadas e as prescrições que orientam suas atividades é essencial para a construção de projetos políticos-pedagógicos consistentes com a formação de profissionais qualificados e com maior potencial de empregabilidade.

Com esta pesquisa, pretende-se traçar panorama sobre os estudos desenvolvidos por pesquisadores e destacar o avanço da temática do trabalho na literatura científica da área de CI no Brasil, considerando a diversidade de seus aspectos na tentativa de identificar as questões inerentes à realidade sociotécnica que tangenciam as discussões sobre a formação e atuação do profissional da informação, em especial seu grupo tradicionalmente representativo, formado por bibliotecários.

\section{Procedimentos metodológicos}

Trata-se de um estudo cientométrico com o objetivo de analisar a produção científica da área da CI sobre a temática "trabalho e informação", especificamente os desafios impostos pelas alterações no mundo do trabalho em função dos novos ambientes de produção e consumo da informação, bem como 
o estudo do impacto das tecnologias nas atividades de trabalho voltadas à informação.

O estudo cientométrico envolveu um estudo bibliométrico das produções científicas no período de seis eventos (2007-2012), além da identificação do movimento de pesquisadores de outros grupos de trabalho sobre o tema "Trabalho". A análise de conteúdo desses textos propiciou um panorama dos problemas abordados e das preocupações dos pesquisadores em relação a esta temática.

Foram eleitos como fonte de pesquisa os Anais dos Encontros Nacionais de Pesquisa em Ciência da Informação (ENANCIB), no período de 2007 a 2012, por ser o evento nacional mais representativo da produção de pesquisas na área de Ciência da Informação. O levantamento dos trabalhos apresentados nos Grupos de Trabalho (GT1 ao GT11) considerou a formação desses grupos ao longo das edições dos ENANCIB e as propostas expressas em suas ementas, observando especificamente os trabalhos que tratam das temáticas: trabalho, informação, formação e tecnologia.

Vale ressaltar que a proposta do GT6: "Informação, Educação e Trabalho" se dedica à abordagem do campo de trabalho informacional; contudo, a busca da temática "Trabalho" nos demais GTs visa contribuir, de maneira complementar, com a formação dos indicadores de estudos sobre o trabalho, considerando a possibilidade da problemática não estar circunscrita às exposições do GT6.

Essa opção metodológica amplia a possibilidade de conhecer, pelo estudo das comunicações, a atuação dos profissionais da informação em espaços diversificados além das bibliotecas universitárias, locus privilegiado para análise da formação e atuação dos bibliotecários, observado em vários estudos apresentados no GT6 da ANCIB (FUJINO; SILVA, 2012).

A coleta de dados foi realizada durante os meses de dezembro de 2013 e janeiro de 2014 nos anais dos eventos no portal da Associação Nacional de Pesquisa e Pós-Graduação em Ciência da Informação - ANCIB (www.ancib.org.br) e nos sítios dos $\mathrm{ENANCIB}^{1}$. A escolha do período para a pesquisa (2007 a 2012) considerou a nova configuração da ementa do GT6 a 
partir de 2007, quando passou a incorporar as temáticas "Informação, Educação e Trabalho".

Entretanto, o objetivo do estudo foi ampliar a pesquisa sobre as discussões relativas ao trabalho do profissional da informação, especialmente no momento em que a adesão tecnológica se apresenta amplamente disseminada e repercute nos ambientes e atividades de trabalho.

A proposta do levantamento não é exaustiva, tem intenção demonstrativa e prospectiva, mobilizando os subsídios para argumentação e reflexão sobre a temática "Trabalho", integrando pesquisa mais ampla sobre o mundo do trabalho dos profissionais da informação, desenvolvida no Programa de Pós-Graduação em Ciência da Informação da Universidade de São Paulo.

Cabe informar que os Anais do ENANCIB 2009 não estavam completamente disponíveis para consulta, sendo então computados somente os trabalhos direcionados para a entrada "Trabalho", exclusivamente do GT6 no período proposto.

O universo da pesquisa na primeira etapa da seleção dos trabalhos era composto por 1183 itens, que é a somatória das produções elencadas nas edições do ENANCIB e disponibilizadas no portal da ANCIB ou nos sites dos eventos. Como categoria de análise optou-se pela ocorrência das expressões de busca: trabalho e informação, tecnologia, profissional da informação e bibliotecário que poderiam ser encontrados no resumo, palavras-chave ou texto completo.

Após a identificação e captura dos arquivos em formato PDF disponibilizados nos anais dos eventos, as produções foram distribuídas na base de dados elaborada com campos e estruturas pré-definidos no software Microsoft Word. A alimentação da base foi executada a partir dos dados extraídos dos arquivos examinados e identificados pela ocorrência dos descritores pré-definidos.

Considerando o recorte adotado, dos 90 trabalhos exclusivamente pertencentes ao GT6 (no período entre 2007 e 2012) foram selecionados 66 trabalhos que atenderam às expressões de busca. Complementarmente, foram selecionados mais 59 trabalhos, mediante o mesmo processo de análise, relativos à temática nos demais GTs. 
Assim, no total, foram selecionadas 125 comunicações que compuseram a amostra analisada, conforme os critérios expostos. Os estudos foram recuperados e lidos e os dados obtidos foram organizados e tratados. Foram utilizados os softwares MS Word e Excel para a confecção de quadros e gráficos.

Dada a relevância da interpretação do contexto sociopolítico da temática do trabalho, este estudo associa a utilização dos métodos quantitativos e qualitativos, de acordo com a proposta teórica e metodológica de Kobashi e Santos (2006, p. 3):

[...] um conhecimento qualitativo não elimina a quantidade, mas procura-se tomar a medida como meio para compreender e explicar, de modo a quebrar a clivagem entre o modo quantitativo e qualitativo de analisar objetos.

E, ainda, que

[...] os estudos métricos se aproximam, cada vez mais, das ciências ditas "moles" (CHS [ciências humanas e sociais]) porque estas últimas oferecem teorias e modelos que permitem interpretar os dados em contextos culturais, políticos, ideológicos e econômicos distintos. (KOBASHI; SANTOS, 2009, p. 139).

Compreende-se, desta forma, que a análise do tema "Trabalho" na CI, sob a perspectiva das produções acadêmicas, converge para uma apreciação satisfatória.

\section{Análise dos resultados}

Os resultados obtidos são discutidos em quatro partes, considerando a natureza e a abordagem utilizada nos procedimentos de coleta e organização dos itens para discussão. Inicia-se com (i) a apresentação dos autores, relacionando-os aos grupos de trabalho; (ii) as informações sobre a incidência da temática "Trabalho e Informação" nas comunicações no grupo de GTs; (iii) aponta os resultados (dados) da produção temática dos trabalhos no GT6; e, em seguida, (iv) busca-se relacionar os achados e discutir as percepções sobre trabalho e informação no contexto do mundo do trabalho do profissional da informação. 
O estudo contabilizou 125 comunicações, conforme mostra o Gráfico 1, que contemplaram a temática "Trabalho e Informação", especialmente expressos no GT6 (66). Todavia, outros estudos representativos foram publicados nos GT2 - Organização e Representação do Conhecimento (15), GT3 - Mediação, Circulação e Apropriação da Informação (12) e GT4 - Gestão da Informação e Conhecimento nas Organizações (12). Após, prosseguindo a ordem de representatividade, o GT1 - Estudos Históricos e Epistemológicos da CI (9), o GT5 - Política e Economia da Informação (6), o GT8 - Informação e Tecnologia (3) e o GT11 - Informação e Saúde (2).

A média de comunicações/evento ENANCIB que se relacionam à temática desta pesquisa no período avaliado teve variação acentuada com crescimento significativo em 2012. Entretanto, cabe observar que o GT11, que trata da Informação específica para o campo da Saúde, teve início apenas em 2011 e que, em 2009, não foram considerados trabalhos deste tipo em outros GTs pelo fato de os anais não terem sido disponibilizados por meio eletrônico. 
Gráfico 1 - Número de comunicações que relacionam a temática "Trabalho e Informação" apresentados nos Grupos de Trabalho no ENANCIB de 2007 a 2012

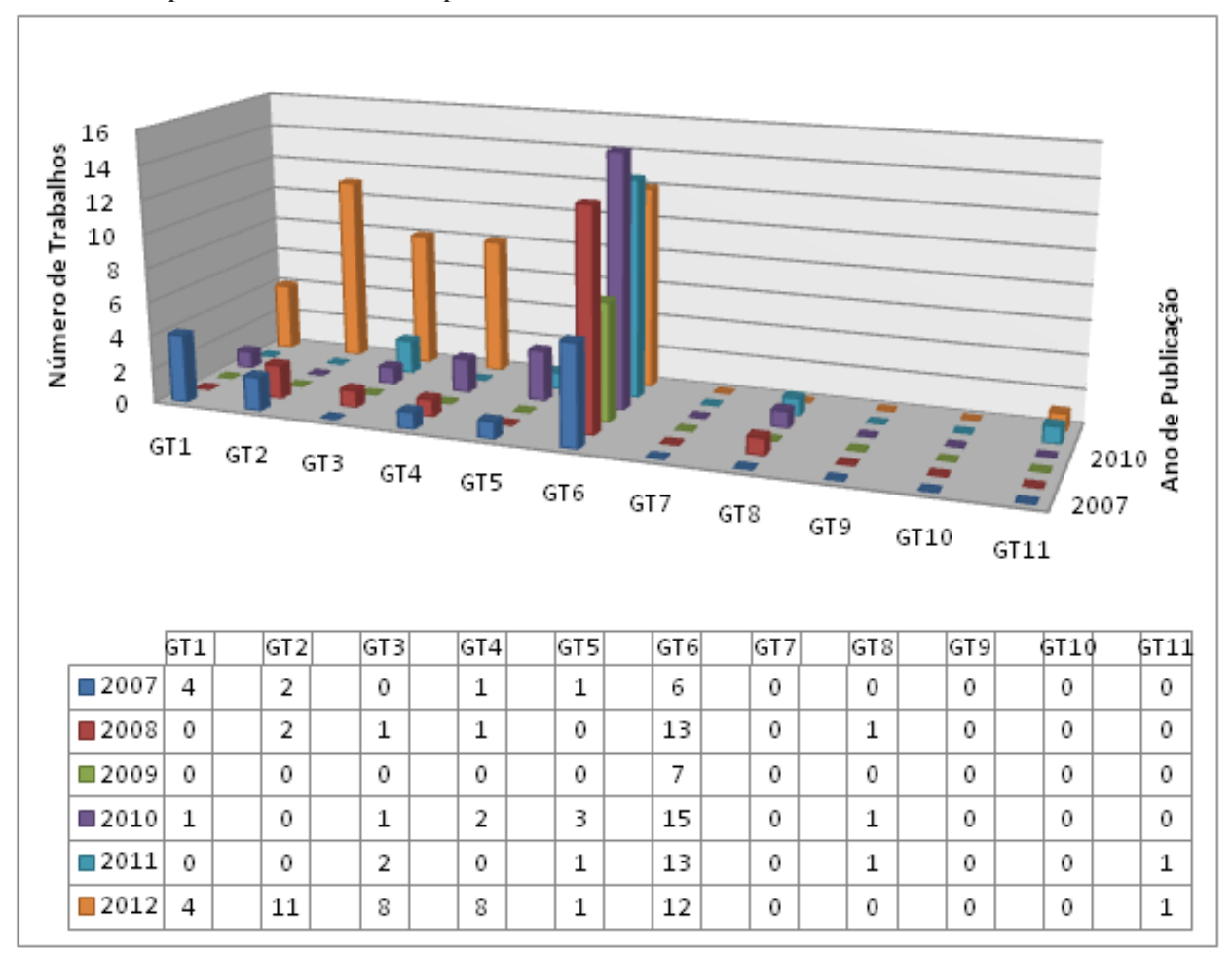

Fonte: elaborado pelas autoras.

Esta produção envolveu 248 autores, com média de 2 autores por trabalho. No entanto, como há autores com densa produção na temática, especialmente no GT6, o número total de autores individuais é menor. Por isso, foram identificados, para efeito de exemplificação, apenas autores com maior número de trabalhos no GT6 no período proposto pelo estudo.

Considerando o período de 6 eventos analisado nessa amostragem, o núcleo de pesquisadores da área é constituído de autores que apresentaram, no mínimo, 3 trabalhos, tais como: Francisco das Chagas de Souza com 5 trabalhos; Maria Helena T. Crivellari com 4 trabalhos e as autoras Asa Fujino, Aida V. Varela e Elizete Vieira Vitorino com 3 trabalhos cada uma.

Contudo, essa análise requer maiores detalhamentos, pois constata-se que pesquisadores do tema na área, já amplamente citados, não necessariamente têm o hábito de submissão de trabalhos ao ENANCIB, como identificado por Sousa (2014) em sua tese de doutorado. 
Para que essa análise ocorra, a incidência desses estudos representa a relevância da temática "Trabalho" e apontam para a mobilização dos pesquisadores em suas linhas de pesquisa, na contextualização social do trabalho e no trabalho com informação. Também, aglutina aspectos teóricos e metodológicos para a constituição do campo de estudos interdisciplinares da CI e dos Estudos do Trabalho, além de ressaltar a visibilidade profissional no campo da informação.

Sobre a perspectiva das tarefas profissionais, o Gráfico 2 exibe a dinâmica da atuação profissional associada à tecnologia e, conforme esperado, o GT6 representa majoritariamente a ocorrência da temática com 66 publicações $(53 \%)$.

Porém, é importante observar que o GT2 - Organização e Representação do Conhecimento com 15 produções (12\%) explicita a preocupação dos pesquisadores com a alteração no perfil de competências necessárias para trabalho com os aspectos de representação e organização da informação, considerando questões de interoperabilidade semântica (ANDRADE; CERVANTES, 2012) e aspectos relativos à interligação de dados abertos (CAMPOS et al., 2012). Por outro lado, o GT3 - Mediação, Circulação e Apropriação da Informação com 12 publicações (10\%) revela a preocupação com o "Trabalho" associado às relações entre políticas de inclusão social e desenvolvimento de competências informacionais (BARI, 2010), aspectos que são relativos aos desafios para mediação em programas de educação à distância (CAVALCANTE, 2012) e mediação literária (CRIPPA, 2012).

Já o GT4 - Gestão da Informação e do Conhecimento com 12 publicações (10\%) apresenta preocupações relativas aos desafios para a educação de usuários nos novos ambientes de trabalho (CARVALHO; AMARAL, 2008) e às novas estruturas organizacionais do mundo do trabalho (SILVA; DUARTE, 2012). Em seguida, o GT1 - Estudos Históricos e Epistemológicos da CI com 9 publicações (7\%) trata de estudos que discorrem das relações entre o mundo do trabalho na perspectiva da discussão sobre suas bases epistemológicas (ORTEGA, 2007; ROBREDO, 2007) nas relações entre a graduação e a pós-graduação (BRAMBILLA, STUMPF, 2007; PINHEIRO, 
2007) nos aspectos éticos da profissão (FREIRE, 2010), ademais nas novas configurações do campo científico (SOUZA, 2012).

O GT5 - Política e Economia da Informação com 6 publicações (5\%) aborda a temática a partir das suas relações com as políticas econômicas ou sociais, tais como a inclusão digital (SOULÉ JÚNIOR, MATTOS, 2007; MASSENSINI; REIS, 2010). De outra forma, o GT8 - Informação e Tecnologia com 3 publicações (2\%) localiza a discussão nos desafios da atuação profissional na web semântica (DUQUE; CARVALHÊDO, 2008).

Por fim, o GT11 - Informação e Saúde, com 2 trabalhos (1\%), por se tratar de um GT cujas pesquisas têm como foco a atuação profissional nos ambientes de saúde, trata das relações do "Trabalho" abordando questões da formação para atuação em ambientes específicos (SANTOS FILHO; CRIVELLARI, 2012) ou, por exemplo, na medicina baseada em evidências (BERAQUET; CIOL; BERALDO, 2011).

Tais pesquisas apontam para uma convergência da discussão da temática "Trabalho", ainda que expressa indiretamente, tendo em vista que os estudos indicam que há intenso interesse em identificar e analisar as relações entre os conceitos da área de CI como informação e conhecimento e as práticas do cotidiano dos profissionais da informação, seja no âmbito público, privado, ou, em especial, em instituições de ensino. 
Gráfico 2 - Incidência percentual de comunicações com a temática "Trabalho e Informação" dos Grupos de Trabalho no ENANCIB de 2007 a 2012

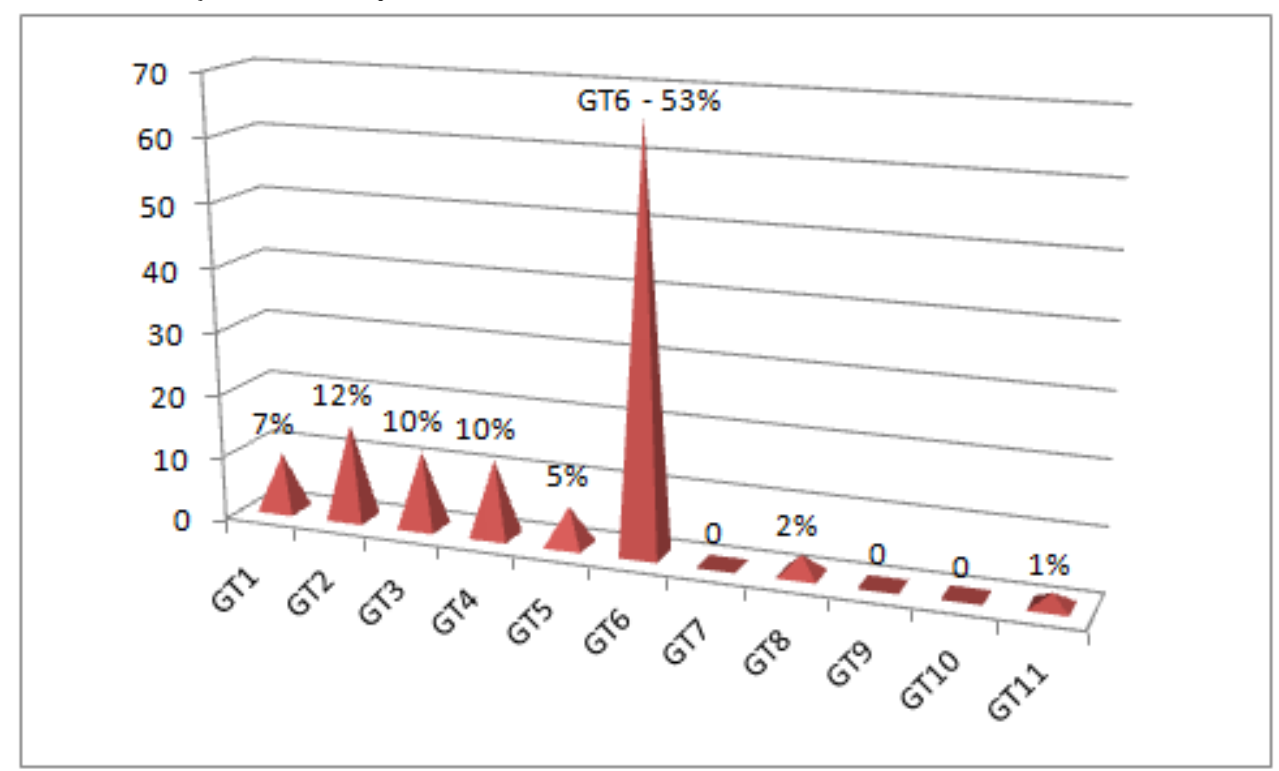

Fonte: elaborado pelas autoras.

Percebe-se a forte incidência de fatores contextuais e características das práticas impactadas com os impositivos tecnológicos, tanto para a adequação ao acesso aos conteúdos informacionais, quanto ao tratamento e organização da informação, somados à percepção do aumento de trabalho do bibliotecário no atendimento às demandas tecnológicas dos usuários.

A análise do conteúdo das comunicações confirma que a organização do processo de produção, ao se transformar em decorrência das mudanças tecnológicas, ajusta-se ao movimento que embasa a concepção da informação como produto de valor agregado. As novas necessidades da sociedade da informação, ao lidar com o volume crescente dos estoques de informação e, ao mesmo tempo, com a complexidade do acesso aos conteúdos informacionais, mobiliza lógicas biblioteconômicas e capacidade crítica para avaliação dos conteúdos, representando um diferencial competitivo para o mercado de trabalho.

Assim, as pesquisas têm como objeto de investigação esse movimento em que o valor da informação foi agregado aos produtos ou aos serviços; às técnicas e tecnologias que interagem com a organização do conhecimento; à avaliação prática do cotidiano dos profissionais da informação e à discussão de 
projetos pedagógicos para a formação de profissionais com as competências adequadas para a complexidade e dinamismo da CI.

Evidenciou-se nos dados percertuais que há um forte compromisso dos autores com o GT6, âmbito das discussões sobre a identidade profissional do bibliotecário contemporâneo e suas práticas profissionais e formação, voltadas para a realidade atual, com um mercado de trabalho modernizado que demanda atualização e inovações curriculares. Esses resultados se articulam e são ratificados pela análise das temáticas recorrentes no conjunto de comunicações encaminhadas pelo GT6 no mesmo período, representados no Gráfico 3.

Os descritores extraídos dos trabalhos analisados revelam que há uma intensa investigação sobre a competência informacional e a formação do bibliotecário, associando os efeitos das mudanças da área com a "explosão informacional" no campo de atuação do profissional da informação.

Os resultados também reforçam o contexto do ambiente universitário para a pesquisa e busca de respostas sobre as questões técnicas e práticas educacionais. Os descritores Busca da Informação, Formação profissional, Aprendizagem e Mercado de Trabalho se associam ao estudo da realidade brasileira, constituindo-se em um recorte específico do campo da CI quanto ao papel do profissional da informação nos processos de gestão da informação. 
Gráfico 3 - Tendências temáticas do GT6 no ENANCIB de 2007 a 2012

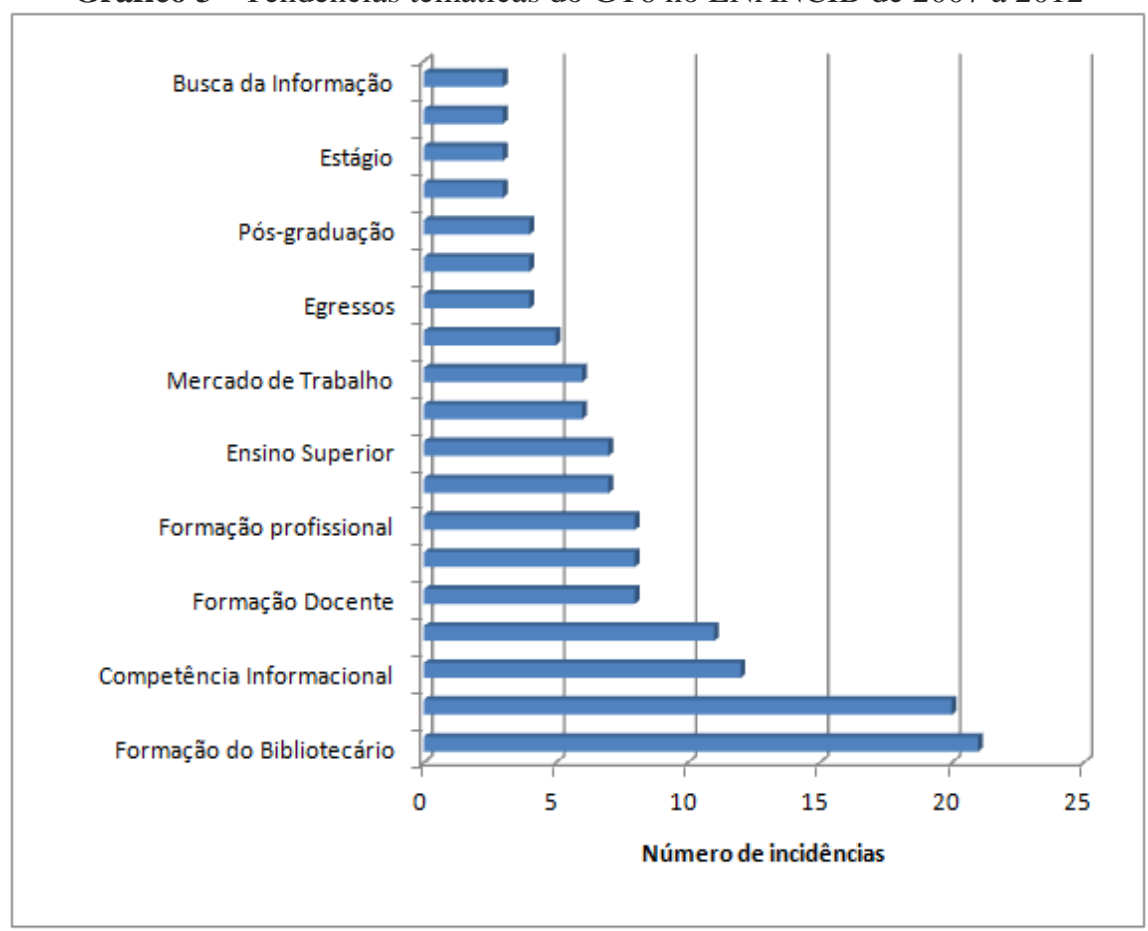

Fonte: elaborado pelas autoras.

Pesquisas ao longo do período analisado mostram diferentes preocupações dos pesquisadores com aspectos do mundo do trabalho neste Grupo de Trabalho em especial, explicitando a integração e complementaridade das discussões. A título de exemplo, citamos Cunha e Silva (2007), que abordam os novos espaços de trabalho para profissionais bibliotecários na Internet; Silva e Gomes (2008) que discutem a autoimagem dos bibliotecários na sociedade da informação; Souza e Stumpf (2009) que refletem sobre os aspectos éticos na CI; Fujino e Vasconcelos (2010) que discutem o estágio na formação acadêmica do profissional da informação; Rodrigues (2011) dá sua contribuição estimulando a reflexão sobre práticas pedagógicas no processo de ensino-aprendizagem e Rocha e Crivellari (2012), que discutem aspectos relativos ao reconhecimento das profissões de informação na atual sociedade.

A variedade das temáticas estudadas mostrou haver convergência quanto à necessidade de estudos sobre a organização do processo produtivo e de trabalho, considerando a possibilidade de atuação do profissional da informação em diferentes serviços e equipes multifuncionais. 
A multiplicidade de estudos sobre competência informacional indica a formação de um referencial teórico da área de CI capaz de entender o processo de mudança da organização do trabalho com a informação que demandam: a capacidade de gerir as contribuições tecnológicas em processos complexos que articulam a necessidade da informação e participação do usuário da informação como coparticipante; a autonomia intelectual capaz de mobilizar conhecimento atualizado em suas tarefas e o compromisso de desenvolver suas competências profissionais.

Compreende-se que pesquisas e estudos de egressos e do ensino superior sobre a formação profissional e a formação do bibliotecário estejam associados e em evidência, porque a organização dos currículos de educação profissional e projetos pedagógicos devem estar alinhados com a formação desse perfil profissional, e que, neste momento, encontram-se em intenso debate.

\section{Considerações finais}

O estudo bibliométrico permite afirmar que há uma contínua reflexão na produção científica sobre as questões do trabalho e informação. Observa-se, no estudo cientométrico, que a temática "Trabalho e Informação" ultrapassa os limites do GT6 do ENANCIB e repercute as questões da formação do profissional da informação e suas práticas nos demais GTs do ENANCIB.

A identificação de pesquisas relacionadas ao tema "Trabalho" no GT1 Estudos Históricos e Epistemológicos da CI confirma positivamente a importância de estudos epistemológicos associados à compreensão do mundo do trabalho dos profissionais da informação a partir dos fatores que reúnem as relações sociais de trabalho, o ambiente de trabalho, as técnicas e tecnologias empregadas e as prescrições que orientam suas atividades como base para a fundamentação de uma área fortemente caracterizada pela prática social no contexto das ciências sociais aplicadas.

Por outro lado, é interessante observar que os trabalhos que se relacionam a essa temática no GT8 - Informação e Tecnologia são 
essencialmente voltados para os desafios da atuação profissional no contexto da web semântica, revelando aspectos essenciais para a construção de projetos políticos-pedagógicos consistentes para a formação de profissionais qualificados e com maior potencial de empregabilidade neste novo ambiente.

A análise dos trabalhos que tratam da relação "Informação e Tecnologia”, por sua vez, mostra que a área superou o desafio de pensar na tecnologia apenas como ferramenta e passou a incorporá-la no processo de concepção do próprio trabalho bibliotecário uma vez que a menção desta relação se dá não apenas pelo uso de instrumentos tecnológicos, mas, principalmente, nos desafios que as alterações no mundo do trabalho trouxe aos profissionais da informação, ampliando suas possibilidades de atuação nos ambientes virtuais.

São temáticas sobre as competências, técnicas, tecnologias, formação, educação e campo de trabalho dos profissionais da informação, confrontadas com os novos requisitos de empregabilidade e acesso às oportunidades de emprego. O estudo mostrou trabalho colaborativo, avanço da literatura e produção de conhecimento na temática do "Trabalho" em CI no Brasil e a preocupação de pesquisadores de diferentes GTs com a formação qualificada e o potencial de atuação dos profissionais da informação em novos ambientes.

\section{Referências}

ANDRADE, M. C. de; CERVANTES, B. M. N. Interoperabilidade semântica entre repositórios institucionais brasileiros: o papel da organização do conhecimento. In: ENCONTRO NACIONAL DE PESQUISA EM CIÊNCIA DA INFORMAÇÃO, 13., 2012, Rio de Janeiro. Anais... Rio de Janeiro: FIOCRUZ, 2012.

BRAMBILLA, S. D. S., STUMPF, I. R. C. Interfaces da informação: tendências temáticas da pós-graduação. In: ENCONTRO NACIONAL DE PESQUISA EM CIÊNCIA DA INFORMAÇÃO, 8., 2007, Salvador. Anais... Salvador: UFBA, 2007.

CAMPOS, L. M. et al. Dados abertos interligados e o espaço do profissional de informação: uma aplicação no domínio da enfermagem. In: ENCONTRO

NACIONAL DE PESQUISA EM CIÊNCIA DA INFORMAÇÃO, 13., 2012, Rio de Janeiro. Anais... Rio de Janeiro: FIOCRUZ, 2012. 
BARI, V. A. A relação entre a inclusão social na universidade brasileira e o desenvolvimento da competência informacional: implicações no campo teórico da ciência da informação e na prática de seus agentes sociais. In: ENCONTRO NACIONAL DE PESQUISA EM CIÊNCIA DA INFORMAÇÃO, 11., 2010, Rio de Janeiro. Anais... Rio de Janeiro: IBICT, 2010.

BERAQUET, V. S. M.; CIOL, R.; BERALDO, D. T. A. Revisão de literatura em ciência da informação e na medicina baseada em evidências: a perspectiva do método para o bibliotecário clínico. In: ENCONTRO NACIONAL DE PESQUISA EM CIÊNCIA DA INFORMAÇÃO, 12., 2011, Brasília, Anais... Brasília: UnB, 2011.

CARVALHO, F. C.; AMARAL; S. A. Educação e estudos de usuários em bibliotecas universitárias brasileiras: abordagem centrada nas competências em informação. In: ENCONTRO NACIONAL DE PESQUISA EM CIÊNCIA DA INFORMAÇÃO, 9., 2008, São Paulo. Anais... São Paulo: USP, 2008.

CASTELLS, M. A sociedade em rede. São Paulo: Paz e Terra, 2006.

CAVALCANTE, L. E. Aprendizagem e competência em informação mediadas em ambientes de educação a distância online na área da saúde. In: ENCONTRO NACIONAL DE PESQUISA EM CIÊNCIA DA INFORMAÇÃO, 13., 2012, Rio de Janeiro. Anais... Rio de Janeiro: FIOCRUZ, 2012.

CRIPPA, G. Mediações literárias da ciência da informação: representações e narrativas de gênero. In: ENCONTRO NACIONAL DE PESQUISA EM CIÊNCIA DA INFORMAÇÃO, 13., 2012, Rio de Janeiro. Anais... Rio de Janeiro: FIOCRUZ, 2012.

CUNHA, M. V.; SILVA, R. A. Os profissionais da informação: espaços de trabalho na internet: segunda parte - 2005-2007. In: ENCONTRO NACIONAL DE PESQUISA EM CIÊNCIA DA INFORMAÇÃO, 8., 2007, Salvador. Anais... Salvador: UFBA, 2007.

DUQUE, C. G.; CARVALHÊDO, S. P. A web semântica, as redes sociais e o futuro dos profissionais da informação. In: ENCONTRO NACIONAL DE PESQUISA EM CIÊNCIA DA INFORMAÇÃO, 9., 2008, São Paulo. Anais... São Paulo: USP, 2008.

FREIRE, I. M. Reflexões sobre uma ética da informação na sociedade em rede. In: ENCONTRO NACIONAL DE PESQUISA EM CIÊNCIA DA INFORMAÇÃO, 11., 2010, Rio de Janeiro. Anais... Rio de Janeiro: IBICT, 2010.

FUJINO, A. Ciência da Informação: relações entre pesquisa, ensino e prática profissional. Revista EDICIC, Marília, v. 1, n. 1, p. 224-261, jan./mar.2011. Disponível em: 
<http://www.edicic.org/revista/index.php?journal=RevistaEDICIC\&page=articl e\&op=view\&path $\% 5 \mathrm{~B} \% 5 \mathrm{D}=19 \&$ path $\% 5 \mathrm{~B} \% 5 \mathrm{D}=\mathrm{pdf}>$. Acesso em: 10 out. 2014.

FUJINO, A.; VASCONCELOS, M. O. Estágios: reflexões sobre a ação didático-pedagógica na formação do profissional da informação. In: ENCONTRO NACIONAL DE PESQUISA EM CIÊNCIA DA INFORMAÇÃO, 11., 2010, Rio de Janeiro. Anais... Rio de Janeiro: IBICT, 2010 .

FUJINO, A.; SILVA, A.A.O.R. Informação e Trabalho: discussão das temáticas no GT6 da ANCIB (2007 A 2012). In: ENCONTRO NACIONAL DE PESQUISA EM CIÊNCIA DA INFORMAÇÃO, 14., 2013, Florianópolis. Anais... Florianópolis: Universidade Federal de Santa Catarina, 2013.

KOBASHI, N. Y.; SANTOS, R.M.N. Arqueologia do trabalho imaterial: uma aplicação bibliométrica à análise de dissertações e teses. In: ENCONTRO NACIONAL DE PESQUISA EM CIÊNCIA DA INFORMAÇÃO, 7., 2006, Marilia. Anais... Marilia: Universidade Estadual de São Paulo, 2006.

KOBASHI, N. Y.; SANTOS, R.M.N. Bibliometria, cientometria, infometria: conceitos e aplicações. Ciência da Informação, Brasília, v. 2, n. 1, p. 155-172, jan./dez. 2009.

PINHEIRO, L. V. R.. Cenário da pós-graduação em ciência da informação no Brasil, influências e tendências. In: ENCONTRO NACIONAL DE PESQUISA EM CIÊNCIA DA INFORMAÇÃO, 8., 2007, Salvador. Anais... Salvador: UFBA, 2007.

MACIAS-CHAPULA, C. O papel da infometria e da cienciometria e sua perspectiva nacional e internacional. Ciência da Informação, Brasilia, v. 27, n. 2, p. 134-140, 1998.

MARCONDES, C. H. Representação e economia da informação. Ciência da Informação, Brasilia, v. 30, n. 1, p. 61-70, jan./abr. 2001.

MASSENSINI, R. L.; REIS, A. S. Inclusão digital no centro vocacional tecnológico Henfil: os desafios à implantação do letramento informacional. In: ENCONTRO NACIONAL DE PESQUISA EM CIÊNCIA DA INFORMAÇÃO, 11., 2010, Rio de Janeiro. Anais... Rio de Janeiro: IBICT, 2010.

ORTEGA, C. D. A documentação como origem e base fértil para a fundamentação da ciência da informação. In: ENCONTRO NACIONAL DE PESQUISA EM CIÊNCIA DA INFORMAÇÃO, 8., 2007, Salvador. Anais... Salvador: UFBA, 2007. 
ROBREDO, J. Ciência da Informação e Filosofia: reflexões. In: ENCONTRO NACIONAL DE PESQUISA EM CIÊNCIA DA INFORMAÇÃO, 8., 2007, Salvador. Anais... Salvador: UFBA, 2007.

ROCHA, E. C. F.; CRIVELLARI, H.M. T. Reconhecimento das profissões da informação: uma leitura a partir de Bourdieu. In: ENCONTRO NACIONAL DE PESQUISA EM CIÊNCIA DA INFORMAÇÃO, 13., 2012, Rio de Janeiro. Anais... Rio de Janeiro: FIOCRUZ, 2012.

RODRIGUES, M. E. F. As práticas pedagógicas no processo de ensino aprendizagem do profissional da informação: desafios e perspectivas de mudanças. In: ENCONTRO NACIONAL DE PESQUISA EM CIÊNCIA DA INFORMAÇÃO, 12., 2011, Brasília. Anais... Brasília: UNB, 2011.

SANTOS FILHO, S.B.; CRIVELLARI, H. M. T. Informação e trabalho em saúde: questões sobre a padronização e novos dispositivos de articulação de práticas informacionais. In: ENCONTRO NACIONAL DE PESQUISA EM CIÊNCIA DA INFORMAÇÃO, 13., 2012, Rio de Janeiro. Anais... Rio de Janeiro: FIOCRUZ, 2012.

SILVA, J. M. O.; DUARTE, E. N. Elementos da cultura informacional (des)favoráveis à implementação da nova estrutura organizacional do sistema de bibliotecas da UFPB. In: ENCONTRO NACIONAL DE PESQUISA EM CIÊNCIA DA INFORMAÇÃO, 13., 2012, Rio de Janeiro. Anais... Rio de Janeiro: FIOCRUZ, 2012.

SILVA, A. L.; GOMES, H. F. A auto-imagem do bibliotecário na sociedade da informação: estudo na cidade de Salvador - Bahia. In: ENCONTRO NACIONAL DE PESQUISA EM CIÊNCIA DA INFORMAÇÃO, 9., 2008, São Paulo. Anais... São Paulo: USP, 2008.

SOULÉ JUNIOR, O.; MATTOS, F. A. M. A influência das crises econômicas das décadas de 80 e 90, no Brasil, no mercado de trabalho dos profissionais ligados as tecnologias da informação. In: ENCONTRO NACIONAL DE PESQUISA EM CIÊNCIA DA INFORMAÇÃO, 8., 2007, Salvador. Anais... Salvador: UFBA, 2007.

SOUZA, E. D. Configurações do campo da ciência da informação: pluralismo epistemológico e descentração interdisciplinar. In: ENCONTRO NACIONAL DE PESQUISA EM CIÊNCIA DA INFORMAÇÃO, 13., 2012, Rio de Janeiro. Anais... Rio de Janeiro: FIOCRUZ, 2012.

SOUZA, F. C.; STUMPF, K. Ética na ciência da informação e biblioteconomia brasileiras: sua discussão em periódicos e anais de eventos. In: ENCONTRO NACIONAL DE PESQUISA EM CIÊNCIA DA INFORMAÇÃO, 10., 2009, João Pessoa. Anais... João Pessoa: UFPB, 2009. 
SPINAK, E. Indicadores cienciométricos. Ci. Info., Brasilia, v. 27, n. 2, p. 141-8, 1998.

\title{
The "Work" Topic in Information Sciences: a scientometric study
}

\begin{abstract}
This article is a scientometric study that has the aim to analyze the scientific production of Information Sciences on the topic "work" presented at ENANCIB in the period of 2007 to 2012. It has the purpose of identifying issues related to the sociotechnical reality that produces discussions about the development of a professional practice for the information professional. It was assumed that understanding the world of work from factors that assemble social relations, techniques, technologies used and the instructions that guide their activities is essential for the construction of pedagogic projects. Therefore, it is considered to apply the new employability requirements so one can access new job opportunities; , besides making use of the relations with the social contexts in which there is a demanding labor market. Results show continuous increasing in information production on the topic, especially in 2012, with the involvement from different Work Groups of ENANCIB on deliberation about skills, techniques, technologies and access to employment opportunities, specifically with aspects of formation and professional practice.
\end{abstract}

Keywords: Information professional. Work. Scientometric study. Development. Professional practice.

\footnotetext{
${ }^{1}$ Com o lançamento do Repositório Benancib, em maio de 2014, que reúne e disponibiliza os anais dos Encontros Nacionais de Pesquisa e Pós-Graduação em Ciência da Informação, é possível realizar a conferência dos dados já coletados para ajustar a pesquisa quando necessário. Disponível em: <http://repositorios.questoesemrede.uff.br/repositorios〉. Acesso em: 30 nov. 2014.
} 
O tema "Trabalho" em Ciência da Informação: estudo cientométrico

Asa Fujino, Adaci A. O. Rosa Silva

Recebido: 31/07/2014

Aceito: 20/04/2015 